\title{
An evaluation and comparison of the height and mass of the top 250 ATP players
}

Keith Leiting (USA)

ITF Coaching and Sport Science Review 2015; 67 (23): 6 - 8

\section{ABSTRACT}

Elite level tennis performance requires perfect skill and highly developed physiological characteristics. Very little research focuses on the physical characteristics of elite level tennis. This evaluation of height and mass suggests that both variables are, on average, larger the closer a player gets to the number one ranking. This suggests that physical characteristics may influence elite level tennis performance.
Key words: ATP, physical characteristics, anthropometrics Received: 22 July 2015

Accepted: 18 August 015 Corresponding author: Keith Leiting Email:

keith.leiting@integrationsports.com

\section{INTRODUCTION}

Development of elite level tennis performance takes years to develop. As the elite tennis player hones their skill and reaches the top 250 in the ATP rankings, the difference in skill between players may be minimal. Several studies have identified important physical characteristics of junior elite tennis players but to the author's knowledge, no studies have been done on the top ATP players. The aforementioned studies suggest that height may positively influence ball velocity (Perry, Wang, Feldman, Ruth, \& Signorile, 2004) and increasing strength may improve tennis performance (Groppel \& Roetert, 1992). Due to the similarities in tennis skill at the elite level, physical characteristics may separate the best from the rest.

The purpose of this study is to identify differences in height and weight of the top 250 ATP players.

\section{METHODS}

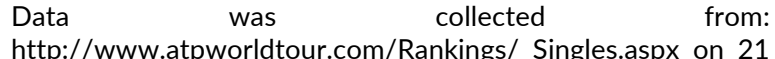
May 2015. Data for each player ranking from 1-250 was manually transferred into Microsoft Excel 2010@. Data included ranking, ATP points, date of birth, height, mass (body weight), and year the player turned pro (experience at the pro level). Player data was separated in 50 player increments. Statistical analysis included 20 two-tailed, student sample ttests assuming unequal variance $(P<0.05)$. Secondary analysis involved Cohen's d estimate of effect size (how practically different are the results). Table 1 shows the number of data sets used for each variable.

\begin{tabular}{|c|c|c|c|c|c|}
\hline \multicolumn{7}{|c|}{ Number of samples analyzed for each sample } \\
\hline Rank & $1-50$ & $51-100$ & $101-150$ & $151-200$ & $201-250$ \\
\hline Points & 50 & 50 & 50 & 50 & 50 \\
\hline Age & 50 & 50 & 50 & 50 & 50 \\
\hline Height (cm) & 50 & 49 & 49 & 45 & 39 \\
\hline Mass (kg) & 50 & 49 & 48 & 46 & 36 \\
\hline Experience as pro & 48 & 47 & 39 & 29 & 19 \\
\hline
\end{tabular}

Table 1. The table above denotes the energy utilisation systems in five discrete categories, however, many other texts combine them into three major systems.

Limitations

This study is limited by the potential inaccuracies and missing data on the www.atpworldtour.com website. If players do not report or update their information we do not know if they have grown taller, gained mass, or lost mass.

\section{RESULTS}

The results of this study indicated that there are statistically significant differences in points, age, height, mass, and experience as a pro player. The difference in points was expected as the players were separated by ranking, which is determined by points. Age and experience as a pro player were randomly statistically significant from the top 50 players, 51100 and 151-200 were statistically significant but not statistically significant for 101-150 and 201-250. Therefore, age and experience as a pro provide no separation between the top 250 ATP players. Height and mass did not reach statistical significance until the top 50 were compared with the 201- 250 ranked players. It is important to note that height and mass show a trending decrease from the top 50 players. Table 2 lists the mean, standard deviation, statistical significance, and Cohen's d effect size for all variables.

\begin{tabular}{|c|c|c|c|c|c|c|}
\hline \multicolumn{7}{|c|}{ Comparison of the top 250 ATP players, in 50 player increments } \\
\hline Rank & & $1-50$ & $51-100$ & $101-150$ & $151-200$ & $201-250$ \\
\hline Points & $\begin{array}{l}\text { Moy..ET } \\
\text { Signification } \\
\text { Cohen`s d }\end{array}$ & $\begin{array}{c}2351.68 \pm \\
2398.39 \\
0.000^{*}\end{array}$ & $\begin{array}{c}685.24^{ \pm} \\
111.61 \\
0.000^{\star} \\
1.33\end{array}$ & $\begin{array}{c}435.38 \pm \\
49.67 \\
0.000^{\star} \\
1.56\end{array}$ & & $\begin{array}{c}215.76 \pm \\
14.01 \\
0.000^{\star} \\
1.77\end{array}$ \\
\hline Age & $\begin{array}{l}\text { Moy..ET } \\
\text { Signification } \\
\text { Cohen`s d }\end{array}$ & $\begin{array}{c}28.54^{ \pm} \\
3.66\end{array}$ & $\begin{array}{c}26.91 \pm \\
3.8 \\
0.030^{\star} \\
0.44^{+}\end{array}$ & $\begin{array}{c}28.18 \pm \\
4.22 \\
0.644 \\
0.09\end{array}$ & $\begin{array}{c}25.83^{ \pm} \\
4.01 \\
0.001^{\star} \\
0.71\end{array}$ & $\begin{array}{c}27.13 \pm \\
13.11 \\
0.465 \\
0.17\end{array}$ \\
\hline $\begin{array}{l}\text { Height } \\
\text { (cm) }\end{array}$ & $\begin{array}{l}\text { Moy..ET } \\
\text { Signification } \\
\text { Cohen's d }\end{array}$ & $\begin{array}{c}188.32 \pm \\
8.17\end{array}$ & $\begin{array}{c}185.82 \pm \\
6.42 \\
0.093 \\
0.34^{+}\end{array}$ & $\begin{array}{c}185.80 \pm \\
6.47 \\
0.091 \\
0.34^{+}\end{array}$ & $\begin{array}{c}185.62 \pm \\
6.66 \\
0.080 \\
0.36\end{array}$ & $\begin{array}{c}184.26 \pm \\
5.03 \\
0.005^{*} \\
0.62\end{array}$ \\
\hline $\begin{array}{c}\text { M a s } s \\
(\mathrm{~kg})\end{array}$ & $\begin{array}{l}\text { Moy..ET } \\
\text { Signification } \\
\text { Cohen`sd }\end{array}$ & $\begin{array}{c}81.70 \pm \\
8.43\end{array}$ & $\begin{array}{c}79.24 \pm \\
6.75 \\
0.112 \\
0.32+\end{array}$ & $\begin{array}{c}79.78 \pm \\
7.07 \\
0.223 \\
0.25^{+}\end{array}$ & $\begin{array}{c}79.47 \pm \\
6.05 \\
0.138 \\
0.31+\end{array}$ & $\begin{array}{c}77.30 \pm \\
5.79 \\
0.004^{*} \\
0.62\end{array}$ \\
\hline $\begin{array}{l}\text { Experi- } \\
\text { ence as } \\
\text { a pro }\end{array}$ & $\begin{array}{l}\text { Moy..ET } \\
\text { Signification } \\
\text { Cohen`s d }\end{array}$ & $\begin{array}{c}10.73 \pm \\
3.46\end{array}$ & $\begin{array}{c}9.17 \pm \\
3.52 \\
0.032^{*} \\
0.45^{+}\end{array}$ & $\begin{array}{c}10.85 \pm \\
4.09 \\
0.888 \\
-0.03\end{array}$ & $\begin{array}{c}8.69^{ \pm} \\
4.25 \\
0.034^{\star} \\
0.53^{+}\end{array}$ & $\begin{array}{c}9.16 \pm \\
4.51 \\
0.183 \\
0.39+\end{array}$ \\
\hline
\end{tabular}

Table 2. *Indicates statistical significance at $P<0.05$; Cohen's $d$ : small effect 0.2-0.49 (¥), moderate effect 0.5-0.79 (\$), large effect) $0.8(\neq)$ 


\section{DISCUSSION}

Height

The top 250 ATP players are an elite level group and can be considered homogenous. The top 250 ATP players represent only a small percentage of the tennis players in the world. Therefore, the difference in height among this sample suggests that height may play a role in reaching elite level tennis performance. The analysis of height also shows a downward trend as you get further from the top players. Height may be an advantage because taller players typically have a greater arm span. According to Reeves, Varakamin, \& Henry, (1996) height and arm span are positively correlated $(r=0.73-0.89)$ meaning the taller the individual typically, the greater the arm span. The increase in arm span may positively influence racquet velocity and subsequent ball velocity during the serve and ground strokes.

For example, if a player that is $170 \mathrm{~cm}$ and a player that is $190 \mathrm{~cm}$ have the same shoulder angular velocity, the linear velocity of the racquet will be greater for the taller player. With all other variables the same, the taller player should hit the ball with greater force and velocity. In previous research player height was shown to positively influence ball velocity during the execution of ground strokes and serves (Perry et al., 2004).

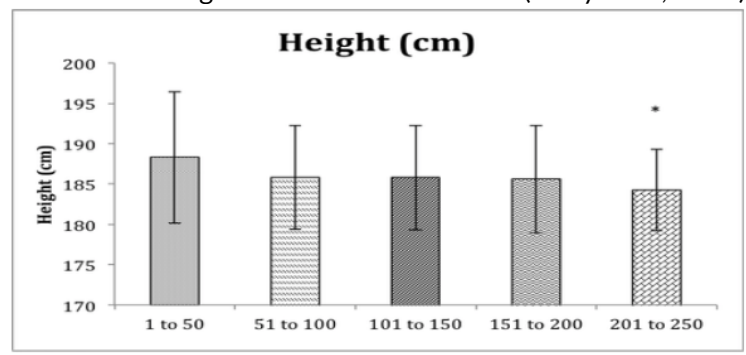

Graph 1. Comparison of height among the top 250 ATP players.

${ }^{*}$ indicates statistical significance from the top 1-50 players. Another positive effect of being a taller player is the ability to cover more of the court with a simple reach of the arm. The size of the court is not changing therefore; longer arms allow the player to cover more of the court without moving their center of mass thus, saving valuable energy.

\section{Mass}

The body mass of the top 250 ATP players shows a downward trend the further a player is from the number one ranking. Data from this analysis suggests that the top 50 players are on average $2-4.5$ kilograms heavier than other ATP players. According to Groppel \& Roetert, (1992) elite level tennis players have $10.4 \pm 3.2 \%$ body fat. The difference in body mass between the top 50 and remaining ATP players may be due to an increase in muscle mass, not fat mass. The increase in muscle mass may give the player an advantage as Gabbett, Kelly, \& Sheppard, (2008) suggested, stronger players are able to change direction and cover more distance faster than weaker players.

Analysis of experience as a pro player showed that on average each group of players had between eight and ten years of experience at the pro level. Analysis of height and mass suggests, as a player progresses through the ATP rankings, physical characteristics may play a larger role in success. Skill and experience are still important, but because everyone at the elite level has similar skill and experience, this may not be the defining factor between winning and losing.

Among the height and mass data, there is a consistent trend that moves downward as a player is further from the number one ranking. The downward trend supports the notion that height and mass may play an important part when attempting to be the best tennis player in the world. Mass(kg)

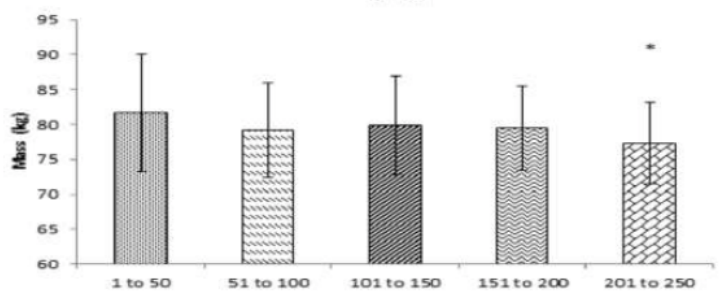

Graph 2. Comparison of mass among the top 250 ATP players.

\section{CONCLUSION}

As mentioned, age and experience were not that different among the top 250 players. The lack of large differences in age and experience suggest that physical characteristics may influence success more than age or experience. The combination of greater height and body mass may create, what is called a "heavy ball." The heavy balls typically have a lot of velocity and spin, which may make the return more difficult technically and physically.

The downward trend in height suggests that a taller player has a greater chance of making it to the elite level. Therefore, if a tennis academy or coach is going to invest in or sponsor an athlete, it may be wise to consider the player's maturation height. Mass also showed the downward trend which; suggests that participating in a quality strength program may increase muscle mass and improve the athlete's performance.

Further research needs to be conducted on elite ATP players to determine the influence of physical characteristics (aerobic, anaerobic, strength, and power) on tennis success.

\section{REFFERENCES}

Gabbett, T. J., Kelly, J. N., \& Sheppard, J. M. (2008). Speed, change of direction speed, and reactive agility of rugby league players. The Journal of Strength \& Conditioning Research, 22(1),174181.https://doi.org/10.1519/JSC.0b013e31815ef7 00

Groppel, J. L., \& Roetert, E. P. (1992). Applied physiology of tennis. Sports Medicine, 14(4), 260268.https://doi.org/10.2165/00007256199214040-00004

Perry, A. C., Wang, X., Feldman, B. B., Ruth, T., \& Signorile, J. (2004). Can Laboratory-Based Tennis Profiles Predict Field Tests of Tennis Performance? The Journal of Strength \& Conditioning Research, 18(1), 136-143.https://doi.org/10.1519/00124278200402000-00020

Reeves, S. L., Varakamin, C., \& Henry, C. J. (1996). The relationship between arm-span measurement and height with special reference to gender and ethnicity. European Journal of Clinical Nutrition, 50(6), 398400.

RECOMMENDED ITF TENNIS ACADEMY CONTENT (CLICK BELOW)

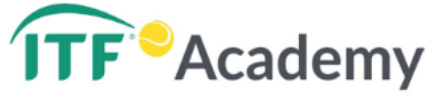


Copyright (c) Keith Leiting 2015

\section{(c) (1)}

This text is under a Creative Commons BY 4.0 license
You are free to Share - copy and redistribute the material in any medium or format - and Adapt the content - remix, transform, and build upon the material for any purpose, even commercially under the following terms:

Attribution: You must give appropriate credit, provide a link to the license, and indicate if changes were made. You may do so in any reasonable manner, but not in any way that suggests the licensor endorses you or your use.

CCBY 4.0 license terms summary $\quad$ CCBY 4.0 license terms 